\title{
Aqueductal CSF Stroke Volume Is Increased in Patients with Idiopathic Normal Pressure Hydrocephalus and Decreases after Shunt Surgery
}

\author{
(D). Shanks, (DK. Markenroth Bloch, (D) K. Laurell, DK.G. Cesarini, (D) M. Fahlström, (DE.-M. Larsson, and (D). Virhammar
}

\begin{abstract}
BACKGROUND AND PURPOSE: Increased CSF stroke volume through the cerebral aqueduct has been proposed as a possible indicator of positive surgical outcome in patients with idiopathic normal pressure hydrocephalus; however, consensus is lacking. In this prospective study, we aimed to compare CSF flow parameters in patients with idiopathic normal pressure hydrocephalus with those in healthy controls and change after shunt surgery and to investigate whether any parameter could predict surgical outcome.
\end{abstract}

MATERIALS AND METHODS: Twenty-one patients with idiopathic normal pressure hydrocephalus and 21 age- and sex-matched healthy controls were prospectively included and examined clinically and with MR imaging of the brain. Eighteen patients were treated with shunt implantation and were re-examined clinically and with MR imaging the day before the operation and 3 months postoperatively. All MR imaging scans included a phase-contrast sequence.

RESULTS: The median aqueductal CSF stroke volume was significantly larger in patients compared with healthy controls (103.5 $\mu$ L; interquartile range, $69.8-142.8 \mu \mathrm{L}$ ) compared with $62.5 \mu \mathrm{L}$ (interquartile range, 58.3-73.8 $\mu \mathrm{L} ; P<.01$ ) and was significantly reduced 3 months after shunt surgery from $94.8 \mu \mathrm{L}$ (interquartile range, 81-241 $\mu \mathrm{L}$ ) to $88 \mu \mathrm{L}$ (interquartile range, 51.8-173.3 $\mu \mathrm{L} ; P<.05$ ). Net flow in the caudocranial direction (retrograde) was present in 11/21 patients and in 10/21 controls. Peak flow and net flow did not differ between patients and controls. There were no correlations between any CSF flow parameters and surgical outcomes.

CONCLUSIONS: Aqueductal CSF stroke volume was increased in patients with idiopathic normal pressure hydrocephalus and decreased after shunt surgery, whereas retrograde aqueductal net flow did not seem to be specific for patients with idiopathic normal pressure hydrocephalus. On the basis of the results, the usefulness of CSF flow parameters to predict outcome after shunt surgery seem to be limited.

ABBREVIATIONS: ACSV = aqueductal CSF stroke volume; iNPH = idiopathic normal pressure hydrocephalus; IQR = interquartile range; MMSE = Mini-Mental State Examination; $\mathrm{NPH}=$ normal pressure hydrocephalus; $\mathrm{PC}=$ phase-contrast; $\mathrm{TUG}=$ Timed Up and Go Test

diopathic normal pressure hydrocephalus (iNPH) is a disease of the elderly population, presenting with a triad of gait disturbance, progressive dementia, and urinary incontinence. ${ }^{1}$ Radiologic findings include ventriculomegaly out of proportion to sulcal enlargement and without apparent obstruction of the CSF circulation, often in combination with periventricular white mat-

Received October 10, 2018; accepted after revision December 31.

From the Departments of Surgical Sciences and Radiology (J.S., M.F., E.-M.L.), Neuroscience and Neurosurgery (K.G.C.), and Neuroscience and Neurology (J.V.), Uppsala University, Uppsala, Sweden; Lund University Bioimaging Center (K.M.B.), Lund University, Lund, Sweden; and Department of Pharmacology and Clinical Neuroscience (K.L.), Umeå University, Umeå, Sweden.

Elna-Marie Larsson and Johan Virhammar contributed equally to this work.

Please address correspondence to J. Virhammar, MD, PhD, Department of Neuroscience, Neurology, Uppsala University, Akademiska Sjukhuset, ing 85, 75185 Uppsala, Sweden; e-mail: johan.virhammar@neuro.uu.se; @johanvirhammar

三 Indicates article with supplemental on-line tables.

http://dx.doi.org/10.3174/ajnr.A5972 ter hyperintensities and increased CSF flow through the ventricular system..$^{2-4}$ The disease is treated by CSF diversion, in most cases in the form of a ventriculoperitoneal shunt. Shunting selection criteria vary among different centers, as well as the reported rate of clinical improvement after the operation, with a reported range of $60 \%-80 \%{ }^{5,6}$ Because shunt surgery has potentially serious risks, correctly identifying patients who may benefit from a shunt operation is of clinical importance.

Several previous studies have explored the stroke volume of CSF through the cerebral aqueduct, evaluated by phase-contrast (PC) MR imaging as a predictor of shunt surgery outcome..$^{7-11}$ However, the aforementioned studies have presented contradicting results, and the validity of the method remains in dispute. Also, there are reports of retrograde CSF net flow in patients with iNPH, ${ }^{12-14}$ but few studies have included age-matched controls.

With this prospective study, we aimed to compare aqueductal CSF stroke volume (ACSV), peak flow, and net flow in patients 
Table 1: Demographics and background data in patients and controls ${ }^{a}$

\begin{tabular}{lccc}
\hline & $\begin{array}{c}\text { Patients } \\
(\boldsymbol{n}=21)\end{array}$ & $\begin{array}{c}\text { Controls } \\
(\boldsymbol{n}=21)\end{array}$ & $\begin{array}{c}\boldsymbol{P} \\
\text { Value }\end{array}$ \\
\hline Age (median) (range) (yr) & $74(65-81)$ & $74(65-82)$ & $\mathrm{NS}^{\mathrm{b}}$ \\
Sex (No. of men) (\%) & $11(52 \%)$ & $11(52 \%)$ & $\mathrm{NS}^{\mathrm{c}}$ \\
MMSE & $25(22-27)$ & $30(29-30)$ & $<.001^{\mathrm{d}}$ \\
Urgency scale & $3(1-4)$ & $1(1-1)$ & $<.001^{\mathrm{d}}$ \\
mRS & $2(2-3)$ & $0(0-0)$ & $<.001^{\mathrm{d}}$ \\
TUG (sec) & $20(14-31)$ & $9(8-11)$ & $<.001^{\mathrm{d}}$ \\
TUG (No. of steps) & $22(18-34)$ & $12(11-14)$ & $<.001^{\mathrm{d}}$ \\
10 Meter Walk test (sec) & $12(8-17)$ & $5(5-6)$ & $<.001^{\mathrm{d}}$ \\
10 Meter Walk Test (No. of steps) & $22(16-30)$ & $12(11-13)$ & $<.001^{\mathrm{d}}$ \\
Evans index & $0.35(0.34-0.39)$ & $0.28(0.24-0.30)$ & $<.001^{\mathrm{d}}$ \\
DWMH & $1(1-3)$ & $1(1-2)$ & $\mathrm{NS}^{\mathrm{d}}$ \\
DESH (No.) (\%) & $14(67 \%)$ & $0(0 \%)$ & $<.001^{\mathrm{c}}$ \\
Callosal angle & $66^{\circ}\left(60^{\circ}-73^{\circ}\right)$ & $113^{\circ}\left(104^{\circ}-121^{\circ}\right)$ & $<.001^{\mathrm{d}}$ \\
Flow void & $3(2-3)$ & $2(2-2)$ & $\mathrm{NS}^{\mathrm{d}}$ \\
\hline
\end{tabular}

Note:-DWMH indicates deep white matter hyperintensities; DESH, disproportionately enlarged subarachnoid space hydrocephalus; NS, not significant.

a Unless indicated otherwise, data are median, with IQR in parenthesis.

${ }^{b}$ Mann-Whitney $U$ test.

${ }^{c} \mathrm{McNemar}$ test.

${ }^{\mathrm{d}}$ Wilcoxon signed rank test.

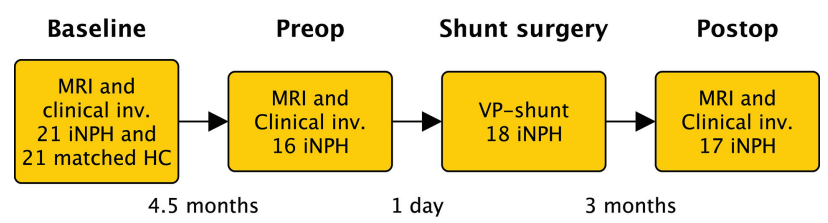

FIG 1. Timeline. MRI indicates MR imaging with the phase-contrast MR imaging sequence; Clinical inv., clinical investigation with tests of gait function, cognition, and urinary symptoms; HC, age- and sexmatched healthy controls. Preop = preoperative investigations; Postop, postoperative follow-up.

with iNPH with those in age- and sex-matched healthy controls and investigate whether any of these CSF flow parameters could function as a predictor of outcome of shunt surgery.

\section{MATERIALS AND METHODS Patients and Controls}

Twenty-six patients with suspected iNPH were prospectively included in the study. After examination by a multidisciplinary normal pressure hydrocephalus (NPH) team consisting of a neurosurgeon, neurologist, physiotherapist, and an occupational therapist, 23 of them were diagnosed with iNPH according to the international guidelines, ${ }^{15}$ whereas 3 were considered to have other conditions. All patients had a typical progressive gait disorder in combination with cognitive dysfunction and/or urgency incontinence, and all patients had findings of enlarged lateral ventricles and tight high-convexity sulci on imaging. MR imaging of the brain and lumbar punctures were performed in the diagnostic work-up.

Twenty-three controls were randomly recruited from the Uppsala municipality using the Swedish population registry and were matched with patients with respect to sex and age ( \pm 2 years). Exclusion criteria were previous stroke or any known neurologic disease, diabetes mellitus, history of myocardial infarction, dependence on walking aids, and any terminal disease. Antihypertensive medication, aspirin, and common pain medications were allowed. Two of the controls did not match any patient; therefore, 21 patient-control pairs were available. The controls did not differ from patients with respect to vascular risk factors. The patients and controls are described in Table 1 , and they were also included in previous studies. ${ }^{16,17}$ The study was approved by the local ethics committee in Uppsala, Sweden, and all patients and controls gave written informed consent for participation.

\section{Time Scheme}

Patients and controls were examined at baseline with MR imaging of the brain and clinical evaluation. Patients were also investigated preoperatively (the day before the operation) with MR imaging and 3 months postoperatively with repeat clinical examinations and MR imaging. The time between baseline and preoperative scans was a median of 4.5 months (interquartile range [IQR], 4-7.75 months; range, 2-11 months), and time between the operation and postoperative MR imaging was 3 months (IQR, 2-4 months; range, 2-8 months; Fig 1).

The study comprised 2 parts-Part 1: baseline scans of patients were compared with those of matched healthy controls; and Part 2: baseline, preoperative, and postoperative scans of patients were compared with investigate longitudinal differences across time and the predictive values of the CSF flow parameters.

All 21 patients with iNPH were offered shunt surgery. Two patients dropped out of Part 2 of the study, and 1 died before surgery. The 18 patients still included in the study underwent shunt surgery. One of the 18 patients included in Part 2 of the study did not match any healthy control and was therefore not included in Part 1 (the patient with the highest ACSV at baseline in Fig 2B).

Baseline MR imaging was performed in all 18 patients; however, in 2 patients, the preoperative scans were missing, and in 1 patient, the postoperative flow-quantification scans were lost due to technical issues. Data of the baseline scan were used in the patient who was investigated postoperatively but with a missing preoperative investigation in the longitudinal comparison.

Four patients underwent a re-operation within 3 months: 1 related to a shunt infection, 2 with adjustments to the proximal catheter, and 1 due to bowel perforation. All patients were initially implanted with a ventriculoperitoneal shunt with a Strata valve (Medtronic, Dublin, Ireland). The patient with a bowel perforation after the first operation underwent a re-operation with a ventriculoatrial shunt. The postoperative MR imaging and follow-up visit were performed 3 months after the re-operation in these 4 patients.

\section{Clinical Examination}

The clinical examination consisted of a standard neurologic examination, the Mini-Mental State Examination (MMSE), mRS, the Timed Up and Go Test (TUG), time and number of steps required to walk $10 \mathrm{~m}$ at maximum pace, and the gait and balance tests from the iNPH scale. ${ }^{18}$ Tests of gait function were performed 

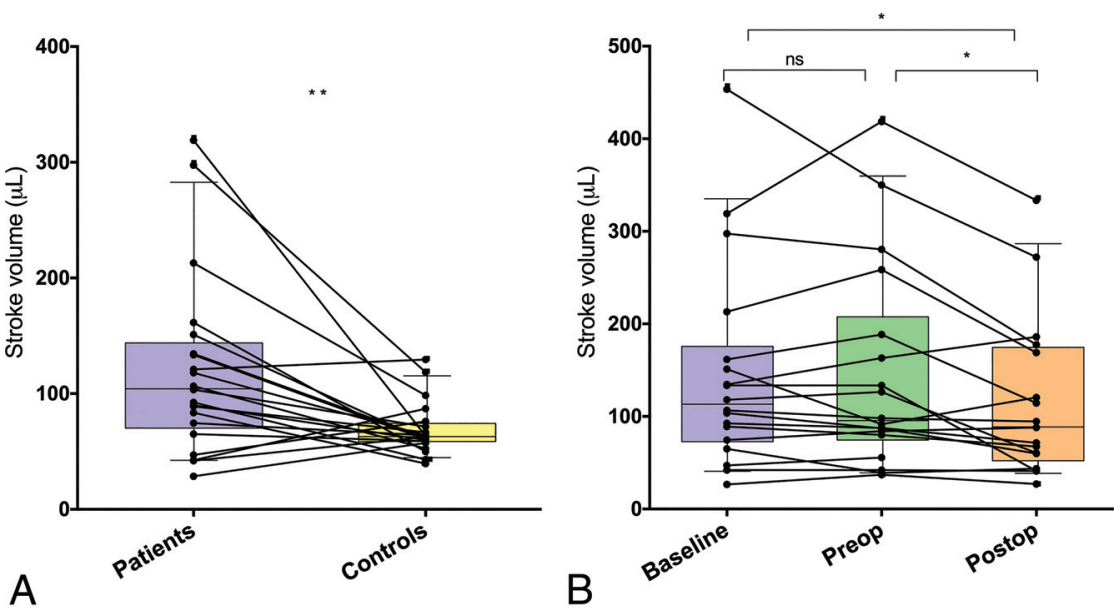

FIG 2. A, Aqueductal cerebral stroke volume in patients with iNPH and healthy controls. The lines connect each patient with a matched control. $B$, Aqueductal cerebral stroke volume in patients with iNPH at baseline, the day before shunt surgery (preop), and at 3 months after the operation (postop). Error bars represent 10th and 90th percentiles. The asterisk indicates $P<.05$; double asterisks, $P<.01$; NS, not significant.

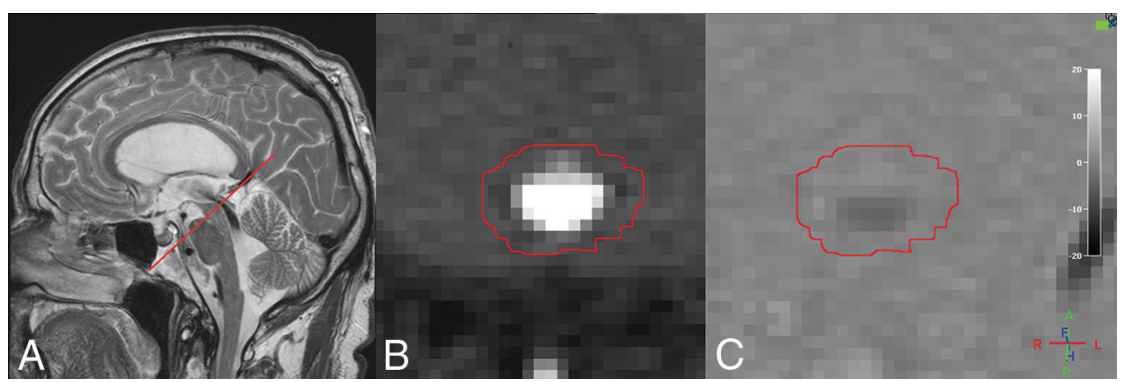

FIG 3. A, Sagittal T2-weighted turbo spin-echo image (without flow compensation) with the red line illustrating the location of the phase-contrast MR imaging scan plane. $B$, Transverse magnitude image through the aqueduct. The red circle illustrates the ROI drawn for flow measurements. C, Corresponding velocity (phase) image.

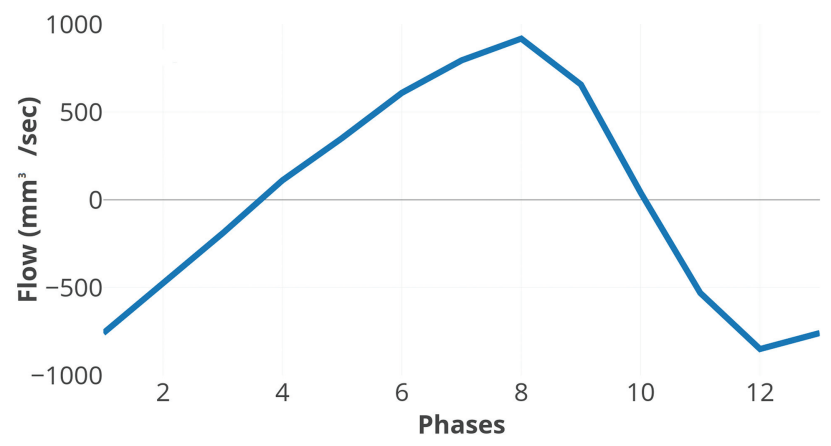

FIG 4. Aqueductal CSF flow during 1 cardiac cycle. Positive values are in the craniocaudal direction.

twice, and the mean value of the 2 trials was used in the statistical analysis. To reduce the number of variables in the correlation analyses, we created a quantitative gait variable, which was the mean of the number of steps and seconds for both the 10 Meter Walk Test and the TUG. The same examinations were repeated at postoperative follow-up. Variables used in the statistical analyses of postoperative outcome were differences in the quantitative gait variable and MMSE. Results of clinical tests from preoperative and postoperative investigations are documented On-line Table 1.

\section{Imaging}

MR imaging was performed on a $3 \mathrm{~T}$ Achieva System (Philips Healthcare, Best, the Netherlands) using a 32-channel head coil with the patient in the supine position. Imaging parameters for the PC MR imaging were as follows: acquired voxel size $=0.59 \times 0.84 \times 4.00$ $\mathrm{mm}$ (reconstructed to $0.59 \times 0.59 \times$ $4.00 \mathrm{~mm}$ ), acquisition matrix $=256 \times$ $179, \mathrm{TR}=12 \mathrm{~ms}, \mathrm{TE}=7.5 \mathrm{~ms}$, flip angle $=15^{\circ}$, retrospective cardiac gating with 12 phases using a peripheral pulse unit. The scan was positioned perpendicular to the aqueduct (Fig $3 A$ ), and the phase-correction technique provided by the vendor was applied. All patients were examined once with a velocity-encoding value of $20 \mathrm{~cm} / \mathrm{s}$. To increase accuracy and decrease the risk of velocity aliasing, we then analyzed the peak velocity of CSF and repeated the sequence with a velocity-encoding adjusted to a slightly higher value than the recorded peak velocity in each individual.

Image data were analyzed in the QFlow package (Philips Healthcare) software. An ROI was drawn manually (Fig $3 B,-C)$, with the examiner blinded to clinical data, covering the perimeter of the aqueduct and adjusted, if necessary, in all phases of the sequence. ACSV, defined as the volumetric mean of the caudal and cranial flow of CSF through the aqueduct; net flow during 1 cardiac cycle; peak velocity; and aqueductal area were calculated by the software. Positive values represent the craniocaudal direction. Quantified flow during 1 cardiac cycle is illustrated in Fig 4.

A morphologic 3D T1-weighted sequence and a T2-weighted FLAIR sequence were also included in the MR imaging protocol for descriptive purposes. In addition to aqueductal flow parameters, we measured 5 imaging features: Evans index, ${ }^{19}$ deep white matter hyperintensities according to the Fazekas visual grading scale ${ }^{20}$ disproportionately enlarged subarachnoid space hydrocephalus, ${ }^{4}$ callosal angle, ${ }^{21}$ and the presence of a flow void in the cerebral aqueduct. ${ }^{22}$ The volume of the lateral ventricles was quantified using SyntheticMR (http://www.syntheticmr.com/). ${ }^{23}$

\section{Statistical Analysis}

The difference between patients and matched controls was tested with the Wilcoxon signed rank test except for age, which was tested with the Mann-Whitney $U$ test. Differences between baseline and preoperative and postoperative investigations were tested with the Friedman test, and post hoc analysis was performed with the Wilcoxon signed rank test. Correlations were tested with the Spearman rank correlation coefficient. It has been suggested that patients with iNPH with ACSV twice as high as that in healthy 
controls respond to shunting. ${ }^{24}$ Therefore, differences in outcome between patients with ACSV twice as high as that in the median in controls $(>125 \mu \mathrm{L})$ were compared with patients with ACSV of $<125 \mu \mathrm{L}$, and the difference in outcome was tested with the Mann-Whitney $U$ test. The level of significance was set at $P<$ .05 , and all analyses were performed using SPSS Statistics for Macintosh, Version 23.0 (IBM, Armonk, New York). No corrections for multiple analyses were performed.

\section{RESULTS}

The median ACSV with IQR at baseline was $62.5 \mu \mathrm{L}(58.3-73.8$ $\mu \mathrm{L})$ in controls and $103.5 \mu \mathrm{L}(69.8-142.8 \mu \mathrm{L})$ in patients $(P<$ .01 , Fig $2 A)$. The aqueductal area was also significantly larger in patients than in controls $(P<.001)$, but there was no difference in net flow volume or peak velocity (Table 2 ). The net flow was negative (caudocranial direction) in 11 of 21 patients and in 10 of 21 healthy controls.

The median ACSV was significantly reduced from $94.8 \mu \mathrm{L}$ (IQR, 81-241 $\mu \mathrm{L}$ ) preoperatively to $88 \mu \mathrm{L}$ (IQR, 51.8-73.3 $\mu \mathrm{L}$ ) postoperatively $(P<.05$, Fig $2 B)$. There was also a significant difference between baseline and postoperative investigation $(P<$ .05 ), but not between baseline and preoperative MR imaging (Fig 2). There were no longitudinal differences for net flow, peak velocity, or aqueductal area (Table 3).

In patients, ACSV correlated with peak velocity $(r=0.78, P<$ $.001)$, aqueductal area $(r=0.48, P<.05)$, callosal angle $(r=$ $-0.48, P<.05)$, and flow void $(r=0.53, P<.05)$. There was also a correlation between peak velocity and flow void $(r=0.56, P<$ $.01)$.

At baseline, ACSV correlated with the clinical variables, mRSscore $(r=-0.49, P<.05)$ and performance on quantitative gait tests $(r=-0.43, P<.05)$. Postoperative difference in ACSV correlated with postoperative changes in the mRS score $(r=0.62$, $P<.01)$.

Table 2: Aqueductal stroke volume, peak velocity, and aqueductal area in controls and patients at baseline ${ }^{\mathrm{a}}$

\begin{tabular}{lccc}
\hline & $\begin{array}{c}\text { Healthy } \\
\text { Controls } \\
(\boldsymbol{n}=21)\end{array}$ & $\begin{array}{c}\text { Patient } \\
\text { Baseline } \\
(\boldsymbol{n}=21)\end{array}$ & $\begin{array}{c}\boldsymbol{P} \\
\text { Value }^{\mathbf{b}}\end{array}$ \\
\hline ACSV $(\mu \mathrm{L})$ & $62.5(58.3-73.8)$ & $103.5(69.8-142.8)$ & $<.01$ \\
Peak velocity & $103(79.5-113.5)$ & $103(68.5-166.5)$ & $\mathrm{NS}$ \\
$\quad(\mathrm{mm} / \mathrm{s})$ & & & \\
Net flow $(\mu \mathrm{L})$ & $-2.9(-5.65-2.55)$ & $-1.6(-19-14)$ & $\mathrm{NS}$ \\
Aq area $\left(\mathrm{mm}^{2}\right)$ & $18(15.5-19)$ & $22(19-25)$ & $<.001$ \\
\hline
\end{tabular}

Note:-Aq indicates aqueductal; NS, not significant.

${ }^{a}$ Data are median with IQR in parentheses.

b Wilcoxon signed rank test.

Table 3: Aqueductal stroke volume, peak velocity, and aqueductal area in patients at all assessment times $^{\mathrm{a}}$

\begin{tabular}{lcccc}
\hline & $\begin{array}{c}\text { Patient } \\
\text { Baseline }(\boldsymbol{n}=21)\end{array}$ & $\begin{array}{c}\text { Patient } \\
\text { Preop }(\boldsymbol{n}=16)\end{array}$ & $\begin{array}{c}\text { Patient } \\
\text { Postop }(\boldsymbol{n}=17)\end{array}$ & $\begin{array}{c}\boldsymbol{P} \\
\text { Value }\end{array}$ \\
\hline ACSV $(\mu \mathrm{L})$ & $103.5(69.8-142.8)$ & $94.8(81-241)$ & $88(51.8-173.3)$ & $<.05^{\mathrm{b}}$ \\
Peak velocity $(\mathrm{mm} / \mathrm{s})$ & $103(68.5-166.5)$ & $127(72.5-154.8)$ & $108(71.5-146.5)$ & $\mathrm{NS}$ \\
Net flow $(\mu \mathrm{L})$ & $-1.6(-19-14)$ & $-1.8(-14.5-10.8)$ & $0(-12.5-2.1)$ & NS \\
Aq area $\left(\mathrm{mm}^{2}\right)$ & $22(19-25)$ & $22.5(19.3-25.8)$ & $24(20.5-25.5)$ & NS \\
\hline
\end{tabular}

Note:-Preop indicates preoperative; Postop, postoperative; Aq, aqueductal; NS, not significant.

${ }^{a}$ Data are median with interquartile range in parentheses.

b Wilcoxon signed rank test. Significant difference between baseline and postoperative investigation and between preoperative and postoperative investigation. Comparisons between baseline and preoperative measurements were all nonsignificant.
None of the CSF flow parameters at baseline correlated with the postoperative clinical outcome. Of the 18 patients in Part 2 of the study, ACSV were $>125 \mu \mathrm{L}$ (twice as high as in controls) in 8 patients and $<125 \mu \mathrm{L}$ in 10 patients. There were no significant differences in postoperative outcome in any clinical variable between patients with high ACSV $(>125 \mu \mathrm{L})$ compared with patients with ACSV of $<125 \mu \mathrm{L}$.

In controls, ACSV correlated with peak velocity $(r=0.64, P<$ $.01)$, but not with aqueductal area. Also in controls, ACSV correlated with the Evans index $(r=0.57, P<.01)$, callosal angle ( $r=$ $-0.47, P<.05)$, and flow void $(r=0.47, P<.05)$, and peak velocity correlated with callosal angle $(r=-0.52, P<.05)$ and deep white matter hyperintensities $(r=-0.55, P<.05)$.

There was a correlation between ACSV and quantified ventricular volume in healthy controls $(r=0.46, P<.05)$, but not in patients (On-line Table 2).

Nine patients $(50 \%)$ improved $>10 \%$ in the quantitative gait variable, and 6 patients (33\%) improved $\geq 3$ levels in the MMSE.

\section{DISCUSSION}

\section{Major Findings}

In this study, we found that the stroke volume through the cerebral aqueduct measured by PC MR imaging is larger in patients with iNPH than in age-matched healthy controls. Additionally, ACSV seems to be reduced following shunt surgery. However, preoperative ACSV did not correlate with clinical improvement after shunt surgery in patients with iNPH. Net flow during 1 cardiac cycle was in the caudocranial direction in half of the patients with iNPH as well as in half of the healthy controls. The strength of this study was the consecutive and prospective inclusion of patients who were investigated longitudinally before and after shunt surgery and compared with healthy controls recruited randomly from the general population.

\section{ACSV as a Predictive Test}

The usefulness of MR imaging-based assessment of CSF hydrodynamics in the selection process of patients with iNPH for surgery has been a topic of interest since Bradley et $\mathrm{al}^{7}$ reported a relationship between increased ACSV and favorable shunt response in 1996. Several studies have since then investigated the concept, however with conflicting results. ${ }^{8,10,25,26}$ Consequently, we aimed to further investigate the usefulness of PC MR imagingderived flow parameters in the selection of patients for shunt surgery. Our results do not support the use of increased ACSV as a prognostic marker of surgical outcome. Most more recent studies on the subject have come to similar conclusions, ${ }^{8-11}$ while other studies ${ }^{25,26}$ have presented results in favor of ACSV quantification in the process of surgical selection. Although our study alone cannot conclusively rule out the usefulness of ACSV measured by PC MR imaging as a predictor of shunt surgery outcome, it adds to an existing body of data questioning the viability of the method.

In the article published by Bradley et al, ${ }^{7}$ in 1996 , an ACSV of $\geq 42 \mu \mathrm{L}$ was 
proposed as a marker of favorable shunting outcome. In a more recent publication, it was suggested that ACSV is highly scannerand technique-dependent, and the author proposed that each treatment center should determine a "normal" ACSV for the scanner by examining a number of healthy elderly individuals. An ACSV twice as high as the ACSV in healthy controls was suggested as a potential marker of shunting success. ${ }^{24} \mathrm{We}$ applied this method in the present study but found no significant difference in clinical outcome between patients with an ACSV at least twice that of the controls $(>125 \mu \mathrm{L})$ compared with patients with lower ACSVs.

Comprehensive knowledge regarding the pathophysiology of iNPH remains elusive. Impaired compliance of brain parenchyma and vasculature and white matter ischemia are some of the suggested underlying mechanisms. ${ }^{27,28}$ It has been suggested that a less compliant brain would hamper the Windkessel effect, resulting in increased CSF pulsatility, including ACSV. ${ }^{29}$ In a study investigating the influence of morphologic and hydrodynamic features on the magnitude of ACSV, no parameters except ventricular volume and cross-sectional aqueductal area were correlated with ACSV. ${ }^{30}$ These findings have been reproduced by other authors. ${ }^{10,31}$ In our study, there was a correlation between ACSV and the volume of the lateral ventricles measured with quantitative MR imaging in controls but not in patients. Contradicting results regarding correlation between ACSV and ventricular volume in patients with iNPH could possibly be explained by inclusion of patients with variable disease progression in different studies. Advancing disease may have more impact on ACSV than on ventricular volume. In contrast, there was a moderate negative correlation between callosal angle and ACSV, indicating that callosal angle could be more closely related to disease progress than ventricular volume. However, correlation between ACSV and any morphologic feature does not necessarily imply causation, and the etiology of increased ACSV remains unclear.

There have been reports of variability of ACSV with regard to both short- and long-term time spans. Scollato et $\mathrm{al}^{25}$ published data suggesting a change of ACSV across time in unshunted patients with NPH. Repeat PC MR imaging during 24 months showed a gradual increase of ACSV, followed by a gradual decrease. The authors hypothesized that ACSV reached a peak level once brain atrophy started to set in, which, in turn, resulted in a decrease of ACSV. In the present study, there was no significant difference in ACSV between baseline and the preoperative investigation with a median time interval of 4.5 months. However, the previously described variability of ACSV across time brings further doubt regarding the method as a prognostic marker and could serve as a partial explanation for our inability to correlate preoperative ACSV with surgical outcome in our study.

At baseline, a low ACSV correlated with poor gait function and global functioning measured by the mRS. If ACSV increased with disease progression, one would expect that these correlations would be the opposite. Our findings could possibly be explained by the theories presented by Scollato et $\mathrm{al}^{25}$ who reported that ACSV is reduced in the late stages of the disease.

\section{Elevated ACSV in Patients with iNPH}

Although ACSV did not correlate with shunting outcome, significantly higher ACSV was present in the patient group. Accordingly, higher flow rates and ACSV in iNPH have been described in previously published literature. ${ }^{32-34}$ However, there was a considerable overlap in ACSV between patients and controls in our study, which limits the diagnostic potential of the method. To better investigate the diagnostic potential of ACSV, future studies should include control groups with patients with ventriculomegaly secondary to atrophy ${ }^{35}$ and controls with differential diagnoses such as progressive supranuclear palsy and multiple system atrophy.

\section{Reduced ACSV after Shunt Placement}

Our results indicated a slight reduction in ACSV occurring after the operation. Previous publications have come to similar conclusions. ${ }^{26,36}$ Shunt insertion is performed to drain excess CSF from the ventricular system and act as a form of capacitance system. It seems logical that ACSV would be reduced following shunt placement; with every systolic phase, a portion of the intraventricular CSF will be diverted through the shunt rather than the cerebral aqueduct. Some authors have suggested that brain compliance increases after shunting, which could also contribute to reduced CSF pulsatility. ${ }^{36}$ This finding could potentially imply that an increase in ACSV, after an initial reduction following shunt placement, may be indicative of shunt dysfunction; however, this implication should be investigated in large samples.

\section{Retrograde Net Flow}

It has been reported in several studies that the net flow in some patients with iNPH is directed caudocranially (ie, flow of CSF into the ventricles). ${ }^{12-14,34,37}$ This is often referred to as retrograde flow because the main production site of CSF is believed to be in the plexus choroideus. ${ }^{38}$ Findings of retrograde net flow have been suggested as a technical error. ${ }^{39}$ Others interpret it as an indicator of a major extraventricular source of CSF production in patients with $\mathrm{iNPH}^{12,40}$ that could have an important role in the pathophysiology of the disease. ${ }^{13}$ Representative control groups are missing in many previous studies, but 2 recent studies investigated net flow in iNPH with age-matched controls. ${ }^{13,34}$ Yin et $\mathrm{al}^{13}$ reported that retrograde net flow was more common in iNPH, while Qvarlander et $\mathrm{al}^{34}$ found no difference in the direction of net flow between patients with iNPH and healthy controls. Our results were more similar to those of Qvarlander et al, with no difference between patients and controls regarding the direction of net flow. However, retrograde net flow was a common finding in our study in both patients and healthy controls. How CSF flow direction is related to age in healthy individuals should be studied further before conclusions can be drawn from results in patients with iNPH. There are also reports that retrograde net flow is reversed after shunting, ${ }^{12}$ but we could not replicate that finding.

\section{Limitations}

There were some limiting factors concerning technical aspects of the radiologic examination. The flow curves obtained were based on 12 phases. This is comparable with earlier studies investigating ACSV, though many modern studies have used 30-40 phases. 
However, an increase in temporal resolution would lead to prolonged scan times, which, in turn, would increase the risk of movement artifacts.

The cerebral aqueduct and the measured ACSV are of small magnitude in the context of phase-contrast MR imaging. This makes the measurements particularly susceptible to partial volume effects and phase-background correction methods.

We did not monitor the respiratory cycle of patients during PC MR imaging examinations. Considering that ACSV has been reported to be influenced by breathing, this could potentially lead to less accurate results. ${ }^{41}$ A potential flow-quantification method with both cardiac and respiratory triggering might provide a more precise measurement of ACSV.

Some studies have chosen to place an additional ROI in the static brain parenchyma to measure and correct for any background noise or mass brain movement that may influence flow measurements. This was not required by the manufacturer's recommendations and was not done in our study.

Measurements of net flow are associated with technical difficulties. The quantity of the value is very small and calculated from the much larger bidirectional flow. Therefore, only small variations in the bidirectional flow lead to uncertain estimation of net flow. The IQR of the net flow was large in our patients and could have influenced the results. The scan time for the PC MR imaging sequence is approximately 5-7 minutes, and flow values in an individual patient during this short investigation are not necessarily generalizable to 24 hours in the same patient.

\section{CONCLUSIONS}

Although ACSV was higher in patients with iNPH compared with healthy controls and decreased after shunt surgery in patients with iNPH, quantified flow volumes did not predict outcome after shunt surgery. In addition, there was an overlap in the magnitude of ACSV between patients and controls that limits the diagnostic potential of the method. Retrograde net flow does not seem to be specific for iNPH. On the basis of our findings and previous reports in the literature, we question the usefulness of PC MR imaging-derived flow values for decisions concerning surgical intervention in patients with iNPH.

\section{ACKNOWLEDGMENTS}

The authors thank our NPH team and the MR imaging staff at Uppsala University Hospital, especially Agneta Gustafsson, Anneli Svärling, and Britt-Mari Bolinder.

\section{REFERENCES}

1. Adams RD, Fisher CM, Hakim S, et al. Symptomatic occult hydrocephalus with "normal" cerebrospinal-fluid pressure: a treatable syndrome. N Engl J Med 1965;273:117-26 CrossRef Medline

2. Virhammar J, Laurell K, Cesarini KG, et al. Preoperative prognostic value of MRI findings in $\mathbf{1 0 8}$ patients with idiopathic normal pressure hydrocephalus. AJNR Am J Neuroradiol 2014;35:2311-18 CrossRef Medline

3. Kockum K, Lilja-Lund O, Larsson EM, et al. The idiopathic normalpressure hydrocephalus Radscale: a radiological scale for structured evaluation. Eur J Neurol 2018;25:569-76 CrossRef Medline

4. Hashimoto M, Ishikawa M, Mori E, et al; Study of INPH on neurological improvement (SINPHONI). Diagnosis of idiopathic normal pressure hydrocephalus is supported by MRI-based scheme: a pro- spective cohort study. Cerebrospinal Fluid Res 2010;7:18 CrossRef Medline

5. Sundström N, Malm J, Laurell K, et al. Incidence and outcome of surgery for adult hydrocephalus patients in Sweden. Br J Neurosurg 2017;31:21-27 CrossRef Medline

6. Toma AK, Papadopoulos MC, Stapleton S, et al. Systematic review of the outcome of shunt surgery in idiopathic normal-pressure hydrocephalus. Acta Neurochir (Wien) 2013;155:1977-80 CrossRef Medline

7. Bradley WG Jr, Scalzo D, Queralt J, et al. Normal-pressure hydrocephalus: evaluation with cerebrospinal fluid flow measurements at MR imaging. Radiology 1996;198:523-29 CrossRef Medline

8. Kahlon B, Annertz M, Ståhlberg F, et al. Is aqueductal stroke volume, measured with cine phase-contrast magnetic resonance imaging scans useful in predicting outcome of shunt surgery in suspected normal pressure hydrocephalus? Neurosurgery 2007;60:124-29; discussion 129-30 CrossRef Medline

9. Algin O, Hakyemez B, Parlak M. The efficiency of PC-MRI in diagnosis of normal pressure hydrocephalus and prediction of shunt response. Acad Radiol 2010;17:181-87 CrossRef Medline

10. Ringstad G, Emblem KE, Geier O, et al. Aqueductal stroke volume: comparisons with intracranial pressure scores in idiopathic normal pressure hydrocephalus. AJNR Am J Neuroradiol 2015;36: 1623-30 CrossRef Medline

11. Dixon GR, Friedman JA, Luetmer PH, et al. Use of cerebrospinal fluid flow rates measured by phase-contrast MR to predict outcome of ventriculoperitoneal shunting for idiopathic normal-pressure hydrocephalus. Mayo Clin Proc 2002;77:509-14 CrossRef Medline

12. Ringstad G, Emblem KE, Eide PK. Phase-contrast magnetic resonance imaging reveals net retrograde aqueductal flow in idiopathic normal pressure hydrocephalus. J Neurosurg 2016;124:1850-57 CrossRef Medline

13. Yin LK, Zheng JJ, Zhao L, et al. Reversed aqueductal cerebrospinal fluid net flow in idiopathic normal pressure hydrocephalus. Acta Neurol Scand 2017;136:434-39 CrossRef Medline

14. Kim DS, Choi JU, Huh R, et al. Quantitative assessment of cerebrospinal fluid hydrodynamics using a phase-contrast cine MR image in hydrocephalus. Childs Nerv Syst 1999;15:461-67 CrossRef Medline

15. Relkin N, Marmarou A, Klinge P, et al. Diagnosing idiopathic normal-pressure hydrocephalus. Neurosurgery 2005;57:S4-16; discussion ii-v Medline

16. Virhammar J, Laurell K, Ahlgren A, et al. Arterial spin-labeling perfusion MR imaging demonstrates regional CBF decrease in idiopathic normal pressure hydrocephalus. AJNR Am J Neuroradiol 2017;38:2081-88 CrossRef Medline

17. Virhammar J, Laurell K, Ahlgren A, et al. Idiopathic normal pressure hydrocephalus: cerebral perfusion measured with pCASL before and repeatedly after CSF removal. J Cereb Blood Flow Metab 2014;34: 1771-78 CrossRef Medline

18. Hellström P, Klinge $P$, Tans J, et al. A new scale for assessment of severity and outcome in iNPH. Acta Neurol Scand 2012;126:229-37 CrossRef Medline

19. Evans W. An encephalographic ratio for estimating ventricular enlargement and cerebral atrophy. Arch Neurol 1942;47:931-37 CrossRef

20. Fazekas F, Chawluk JB, Alavi A, et al. MR signal abnormalities at $\mathbf{1 . 5}$ $\mathrm{T}$ in Alzheimer's dementia and normal aging. AJR Am J Roentgenol 1987;149:351-56 CrossRef Medline

21. Ishii K, Kanda T, Harada A, et al. Clinical impact of the callosal angle in the diagnosis of idiopathic normal pressure hydrocephalus. Eur Radiol 2008;18:2678-83 CrossRef Medline

22. Bradley WG Jr, Whittemore AR, Kortman KE, et al. Marked cerebrospinal fluid void: indicator of successful shunt in patients with suspected normal-pressure hydrocephalus. Radiology 1991;178:459-66 CrossRef Medline

23. Warntjes JB, Leinhard OD, West J, et al. Rapid magnetic resonance 
quantification on the brain: Optimization for clinical usage. Magn Reson Med 2008;60:320-29 CrossRef Medline

24. Bradley WG Jr. CSF flow in the brain in the context of normal pressure hydrocephalus. AJNR Am J Neuroradiol 2015;36:831-38 CrossRef Medline

25. Scollato A, Tenenbaum R, Bahl G, et al. Changes in aqueductal CSF stroke volume and progression of symptoms in patients with unshunted idiopathic normal pressure hydrocephalus. AJNR Am J Neuroradiol 2008;29:192-97 CrossRef Medline

26. Abbey P, Singh P, Khandelwal N, et al. Shunt surgery effects on cerebrospinal fluid flow across the aqueduct of Sylvius in patients with communicating hydrocephalus. J Clin Neurosci 2009;16: 514-18 CrossRef Medline

27. Bateman GA. Vascular compliance in normal pressure hydrocephalus. AJNR Am J Neuroradiol 2000;21:1574-85 Medline

28. Bradley WG, Safar FG, Furtado C, et al. Increased intracranial volume: a clue to the etiology of idiopathic normal-pressure hydrocephalus? AJNR Am J Neuroradiol 2004;25:1479-84 Medline

29. Greitz D. Radiological assessment of hydrocephalus: new theories and implications for therapy. Neurosurg Rev 2004;27:145-65; discussion 166-67 Medline

30. Chiang WW, Takoudis CG, Lee SH, et al. Relationship between ventricular morphology and aqueductal cerebrospinal fluid flow in healthy and communicating hydrocephalus. Invest Radiol 2009;44: 192-99 CrossRef Medline

31. Qvarlander S. Analysis of ICP Pulsatility and CSF Dynamics: The Pulsatility Curve and Effects of Postural Changes, with Implications for Idiopathic Normal Pressure Hydrocephalus [thesis]. Umeå: Umeå University; 2013

32. Al-Zain FT, Rademacher G, Meier U, et al. The role of cerebrospinal fluid flow study using phase contrast MR imaging in diagnosing idiopathic normal pressure hydrocephalus. Acta Neurochir Suppl 2008;102:119-23 CrossRef Medline
33. Luetmer PH, Huston J, Friedman JA, et al. Measurement of cerebrospinal fluid flow at the cerebral aqueduct by use of phase-contrast magnetic resonance imaging: technique validation and utility in diagnosing idiopathic normal pressure hydrocephalus. Neurosurgery 2002;50:534-43; discussion 543-44 Medline

34. Qvarlander S, Ambarki K, Wahlin A, et al. Cerebrospinal fluid and blood flow patterns in idiopathic normal pressure hydrocephalus. Acta Neurol Scand 2017;135:576-84 CrossRef Medline

35. Chaarani B, Bader C, Capel C, et al. Estimation of the lateral ventricles volumes from a 2D image and its relationship with cerebrospinal fluid flow. Biomed Res Int 2013;2013:215989 CrossRef Medline

36. Scollato A, Gallina P, Gautam B, et al. Changes in aqueductal CSF stroke volume in shunted patients with idiopathic normal-pressure hydrocephalus. AJNR Am J Neuroradiol 2009;30:1580-86 CrossRef Medline

37. Penn RD, Basati S, Sweetman B, et al. Ventricle wall movements and cerebrospinal fluid flow in hydrocephalus. J Neurosurg 2011;115: 159-64 CrossRef Medline

38. Spector R, Robert Snodgrass S, Johanson CE. A balanced view of the cerebrospinal fluid composition and functions: focus on adult humans. Exp Neurol 2015;273:57-68 CrossRef Medline

39. Wagshul ME, Chen JJ, Egnor MR, et al. Amplitude and phase of cerebrospinal fluid pulsations: experimental studies and review of the literature. J Neurosurg 2006;104:810-19 Medline

40. Lindstrom EK, Ringstad G, Mardal KA, et al. Cerebrospinal fluid volumetric net flow rate and direction in idiopathic normal pressure hydrocephalus. Neuroimage Clin 2018;20:731-41 CrossRef Medline

41. Chen L, Beckett A, Verma A, et al. Dynamics of respiratory and cardiac CSF motion revealed with real-time simultaneous multislice EPI velocity phase contrast imaging. Neuroimage 2015;122: 281-87 CrossRef Medline 